\title{
Fasting during Ramadan: efficacy, safety, and patient acceptability of vildagliptin in diabetic patients
}

This article was published in the following Dove Press journal:

Diabetes, Metabolic Syndrome and Obesity:Targets and Therapy

16 April 2015

Number of times this article has been viewed

\section{Kamran MA Aziz}

Aseer Diabetes Center, Aseer Central Hospital, Ministry of Health, Abha, Saudi Arabia
Correspondence: Kamran MA Aziz Aseer Diabetes Center, Aseer Central Hospital, Ministry of Health, PO Box 34, Abha, Saudi Arabia

Tel +96656836I040

Email drkamran9999@yahoo.com
Abstract: Diabetes management during Ramadan fasting is challenging to the physician in terms of minimizing the risk of hypoglycemia. As compared to oral hypoglycemic agents (OHAs) and sulfonylureas (SUs), which carry a higher and significant risk of hypoglycemia, newer antidiabetic agents such as dipeptidyl peptidase-4 (DPP-4) inhibitors have demonstrated lower risk of hypoglycemia during Ramadan fasting, with better patient compliance. In addition to diabetes education and pre-Ramadan assessments, the physician should also consider use of DPP-4 inhibitors (such as vildagliptin) during Ramadan fasting to minimize the risk of hypoglycemia in type 2 diabetic subjects. Severe episodes of hypoglycemia have been demonstrated in recent research and clinical trials with OHAs/SUs. Conversely, these research observations have also demonstrated comparative safety and efficacy with lower risk of hypoglycemia associated with vildagliptin. Current research review has collected evidence-based clinical trials and observations for the drug vildagliptin to minimize the risk of hypoglycemia during Ramadan fasting, while at the same time focusing the role of diabetes self-management education (DSME), pre-Ramadan assessments, and patient care.

Keywords: hypoglycemia, DPP4-inhibitors, oral hypoglycemic agents, Ramadan fasting, type 2 diabetes, vildagliptin

\section{Introduction}

It has been well documented in medical literature that diabetes management during Ramadan fasting poses challenges to the treating physician; and pre-Ramadan diabetes assessment, evaluations, and diabetes education are important for successful management. ${ }^{1}$ This is because unplanned diabetes management during Ramadan fasting may lead to hypoglycemia. Hence, in the past few decades, efforts have been made by various researchers to manage diabetes during Ramadan fasting without the risk of hypoglycemia. Various strategies and therapies have been adopted in this regard during Ramadan fasting. These include alteration/reduction of the dosages for oral hypoglycemic agents (OHAs) and insulins, and shifting patients from OHAs and insulins to metformin or other agents such as dipeptidyl peptidase-4 (DPP-4) inhibitors.

The increase in hypoglycemic events during the month of Ramadan has been previously reported in the literature. The Epidemiology of Diabetes and Ramadan (EPIDIAR) study has reported a 7.5-fold increase in risk of hypoglycemia in patients with type 2 diabetes. ${ }^{2}$ However, this risk can be reduced by extensive diabetes education and preRamadan medication adjustments. ${ }^{1}$ Hence, Ramadan itself is not a risk, but poor education and use of medications which cause hypoglycemia with high dosages carries a risk.

Hypoglycemia itself has an adverse effect on the quality of life, is an obstacle while managing diabetes (to control glycemia), and is associated with poor compliance to 
medication and treatment. It has also been well documented that skipping meals and a reduced food intake are the main causes for the hypoglycemia during Ramadan fasting. Hence, diabetes education plays a central role, and diabetic patients should be given education and counseling before Ramadan fasting. ${ }^{1,3,4}$ In general, severe hypoglycemia carries a risk of morbidities, with major cardiovascular events such as stroke, myocardial ischemia/failure, and ventricular arrhythmias. ${ }^{5}$ For these reasons, allowing patients to fast/fasting during Ramadan without risk of hypoglycemia is a personal/patientcentered decision.

A study conducted in Saudi Arabia by Aziz ${ }^{1}$ on 1,046 patients has demonstrated that Ramadan fasting itself does not pose a risk to human metabolism or health, but conversely has beneficial health effects on physiological parameters (eg, an opportunity to lose weight) and on chronic disease prevention. This study has demonstrated that this goal can be achieved only by optimal pre-Ramadan assessment and diabetes education. ${ }^{1}$ Similar observations were reported in other studies as well. ${ }^{6-8}$ However, in 2003, Laarijani et $\mathrm{al}^{9}$ demonstrated a slight decrease in fasting serum glucose among healthy subjects during Ramadan fasting. A similar finding has also been demonstrated by Aziz ${ }^{1}$ in the Ramadan study, with the lowest prevalence of hypoglycemia (4.58\%). Contrary to these facts, different studies conducted in the past during Ramadan fasting have demonstrated high prevalence of hypoglycemia during Ramadan fasting (up to $21.7 \%$ ). ${ }^{10-18}$ However, these studies were mostly observational in nature, and patients were not selected before Ramadan for extensive diabetes self-management education (DSME), counseling, assessment for $\mathrm{HbA} 1 \mathrm{c} / \mathrm{creatinine}$, and alteration of therapy. Hence in other words, it can be concluded, in general, that blood glucose levels fall during Ramadan fasting in diabetic and nondiabetic subjects, and prevention of hypoglycemia with medication adjustments/alterations are the basic strategies to manage diabetes during Ramadan fasting.

With this literature background, the current review focuses on a class of medications which does not cause hypoglycemia, both in general and during Ramadan fasting. One of them is DPP-4 inhibitors, and the drug available in the market is vildagliptin. We will focus on the pathophysiology of type 2 diabetes, DPP-4 inhibitors, and the role of vildagliptin during Ramadan fasting.

\section{Pathophysiology of type 2 diabetes, DPP-4 inhibitors, and vildagliptin}

DPP-4 inhibitors are the new oral antidiabetic agents (including vildagliptin sitagliptin, saxagliptin, linagliptin, alogliptin and other agents as well which are under extensive research). These agents/drugs reduce serum glucose concentrations and improve the glycemic control by augmenting the effects of "incretins"; hence this strategy is also called "incretin based therapy" for diabetes management.

Under normal physiological state, the gut, in response to meals, releases hormones called incretins, for example, GLP-1 (glucagon like peptide-1) and GIP (gastric inhibitory polypeptide), which augment biosynthesis and secretion of insulin (known as incretin effect) as well as slow gastric emptying as well. ${ }^{19-24}$ Normally, these incretin hormones are degraded within minutes after their release by the enzyme DPP-4. As the DPP-4 inhibitors, inhibit this enzyme (DPP-4), they enhance or prolong incretin effect.

Contrary to this normal physiology, in diabetic patients the balance between insulin secretion and hepatic glucose production is dysregulated. In type 1 diabetic subjects, there is absolute insulin deficiency due to autoimmunity against $\beta$-cells with destruction of these cells, as compared with type 2 diabetic subjects who exhibit relative insulin deficiency with insulin resistance. ${ }^{25,26}$ Furthermore, absolute or relative hyperglucagonemia, due to deficiency of incretin hormones in diabetic state, is a hallmark of both type 1 and type 2 diabetic subjects. ${ }^{27,28}$ In other words, in type 2 diabetic subjects, there is insulin resistance and hyperglucagonemia. Due to these pathophysiological states, lipolysis and ketosis may worsen the metabolic state leading to diabetic ketoacidosis (DKA) during prolonged fasting, with absolute or relative insulin deficiency. ${ }^{29,30}$ Insulin resistance can be reversed by metformin, and hyperglucagonemia by incretin based therapy. Additionally, vildagliptin has also been shown to improve $\beta$-cell function in type 2 diabetics, apart from enhancing incretin effect. ${ }^{31}$ Other research studies have demonstrated efficacy of vildagliptin to lower HbAlc and improve glycemic control as well. ${ }^{32-36}$ Hence, reversion of diminished incretin effect is also essential to manage diabetes effectively, both in general and during Ramadan fasting, while preventing hypoglycemia at the same time. This can be accomplished successfully by vildagliptin, a DPP-4 inhibitor. One of the interesting phenomena of DPP-4 inhibitor or vildagliptin is that it is blood glucose-dependent and does not cause hypoglycemia when given as monotherapy, which is again a therapeutic advantage of DPP-4 inhibitors/vildagliptin during Ramadan fasting.

\section{Vildagliptin and Ramadan fasting}

In this section the literature for the safety and efficacy of vildagliptin during Ramadan fasting will be reviewed. 
Sulfonylureas (SUs) and oral hypoglycemic agents (OHAs) are still widely used by general practitioners as oral antidiabetic agents, both in general and during Ramadan fasting, because of their ability to effectively reduce $\mathrm{HbA} 1 \mathrm{c}$ and their low cost. ${ }^{37,38}$ However, they carry a higher risk of severe hypoglycemia, especially if dose is not reduced during Ramadan fasting, and special precautions are required, together with individual considerations, especially in older age group. ${ }^{1,39}$ Hence, highly variable rates of hypoglycemia have been reported in published research trials with SUs/OHAs (3\%-40\%) during Ramadan fasting. However, this risk was significantly reduced when vildagliptin was prescribed during Ramadan fasting, and this has also been recently reported in Indo-Pakistani populations from the UK and in cohorts of UK South Asian Muslim patients in the VECTOR (Vildagliptin Experience Compared To gliclazide Observed during Ramadan) study ${ }^{40-42}$ Furthermore, in general, these agents have also been demonstrated to be safer in older age group. ${ }^{43}$

A recent observational study which combined metformin and vildagliptin therapy together with or without OHAs during Ramadan fasting has demonstrated advantage of reduced hypoglycemia incidence. ${ }^{44}$ They have shown one case of severe hypoglycemia in the arm treated with OHA compared to the vildagliptin group, which showed no hypoglycemia event. The hypoglycemia events were 12 times more in the group treated with OHA as compared to the vildagliptin group. Other studies have reported similar results when comparing OHAs with vildagliptin. ${ }^{45}$ Another study conducted on vildagliptin and SUs or OHAs during Ramadan fasting has reported higher incidence of hypoglycemia during Ramadan fasting in the group treated with SU and Metformin vs vildagliptin plus metformin (26 episodes vs 19 episodes); and also reported $\mathrm{HbA} 1 \mathrm{c}$ reduction in the vildagliptin group, however, with insignificant $P$-values. ${ }^{46} \mathrm{~A}$ study conducted by Aziz ${ }^{1}$ has also concluded that the patient group prescribed with DPP-4 inhibitors such as sitagliptin/vildagliptin did not show any episodes of hypoglycemia during Ramadan fasting. A recent review published in Switzerland and France has studied worldwide the role of DPP-4 inhibitors (including vildagliptin) during Ramadan fasting, and has come to the conclusion that the anti-diabetic agents DPP-4 inhibitors could be a more safer option while managing type- 2 diabetes during Ramadan fasting, with a very low risk of hypoglycemia. ${ }^{47}$

Another prospective, noninterventional study published in France to assess real life rate of hypoglycemia during Ramadan fasting in patients with type 2 diabetes and their ongoing dual therapy of metformin-vildagliptin or metformin-sulfonylurea has shown that hypoglycemia as an adverse events (AEs) was higher in SU group as compared to vildagliptin group ( $17.9 \%$ vs $7.5 \% ; P=0.025)$, and better compliance was seen with vildagliptin group. ${ }^{48}$

The VIRTUE (VildagliptIn expeRience compared wiTh sulphonylUreas obsErved during Ramadan) study, which recruited 1,333 patients from 10 different countries worldwide, has demonstrated significantly fewer hypoglycemia events as compared with SU therapy (5.4\% vs $19.8 \%$, respectively; $P<0.001$ ). Additionally, good glycemic and weight control and better tolerance were observed in vildagliptintreated patients. ${ }^{49}$

The STEADFAST (STudy Evaluating vildAgliptin compareD to gliclazide in patients with type 2 diabetes FASTing during Ramadan) study, a multicenter, double-blind, and randomized trial, which recruited 557 type 2 diabetic patients has demonstrated significantly lower hypoglycemia prevalence as compared to SUs (3.0\% vs 7.0\%, respectively; $P=0.039) .{ }^{50}$ Similar results have been reported in the Muslim populations of India. ${ }^{51}$

In summary, vildagliptin has been proven to be effective, well tolerated, and associated with low incidence of hypoglycemia in recent clinical trials. This is true especially in high risk population such as elderly and those with renal impairment or those who require insulin based therapy with metformin and DPP-4 inhibitors. ${ }^{44,52-56}$

\section{Conclusion}

Despite the Islamic rule of exemption, most of the diabetic patients essentially fast during Ramadan; and this fact should be considered while managing diabetes during Ramadan fasting. ${ }^{1,2}$ Drugs such as DPP-4 inhibitors/vildagliptin should be selected with other diabetes medications as these are not associated with high risk of hypoglycemia.

It has been observed that general practitioners have limited knowledge of diabetes management during Ramadan fasting. Furthermore, survey results have shown that $53 \%$ of patients fasted against medical advice. ${ }^{57}$ However, this can be prevented effectively by extensive DSME and Ramadanfocused diabetes management; Ramadan Education and Awareness in Diabetes (READ) program and similar studies have demonstrated promising and good results in terms of minimizing hypoglycemia risk during Ramadan fasting. ${ }^{1,58,59}$ Effective diabetes education for patients' empowerment and motivation with self-care awareness involves health care professional teams, families, the community, and religious authorities as well. ${ }^{60,61}$

Additionally, newer antidiabetic agents, such as vildagliptin (DPP-4 inhibitor), that are associated with lower risk of 
hypoglycemia, are considered to be one of the safer options while managing diabetes during Ramadan fasting, and have also shown higher treatment adherence as compared to other medications. ${ }^{62}$

\section{Disclosure}

The author reports no conflicts of interest in this work.

\section{References}

1. Aziz KM. Effect of fasting Ramadan in diabetes control status - application of extensive diabetes education, serum creatinine with $\mathrm{HbA}_{1 c}$ statistical ANOVA and regression models to prevent hypoglycemia. Recent Pat EndocrMetab Immune Drug Discov. 2013;7(3):233-251.

2. Salti I, Bénard E, Detournay B, et al; EPIDIAR study group. A population-based study of diabetes and its characteristics during the fasting month of Ramadan in 13 countries: results of the epidemiology of diabetes and Ramadan 1422/2001 (EPIDIAR) study. Diabetes Care. 2004;27:2306-2311.

3. Amiel S, Dixon T, Mann R, Jameson K. Hypoglycaemia in type 2 diabetes. Diabet Med. 2008;25:245-254.

4. Alvarez Guisasola F, Tofe' Povedano S, Krishnarajah G, et al. Hypoglycaemic symptoms, treatment satisfaction, adherence and their associations with glycaemic goal in patients with type 2 diabetes mellitus: findings from the Real-Life Effectiveness and Care Patterns of Diabetes Management (RECAP-DM) study. Diabetes Obes Metab. 2008;10(Suppl 1):25-32.

5. Zammitt N, Frier B. Hypoglycemia in type 2 diabetes: pathophysiology, frequency, and effects of different treatment modalities. Diabetes Care. 2005;28:2948-2961.

6. Yarahmadi S, Larijani B, Bastanhagh, et al. Metabolic and clinical effects of Ramadan fasting in patients with type II diabetes. $J$ Coll Physicians Surg Pak. 2003;13:329-332.

7. Khatib F, Shafagoj Y. Metabolic alterations as a result of Ramadan fasting in noninsulin-dependent diabetes mellitus patients in relation to food intake. Saudi Med J. 2004;25:1858-1863.

8. Mygind A, Kristiansen M, Wittrup I, Norgaard LS. Patient perspectives on type 2 diabetes and medicine use during Ramadan among Pakistanis in Denmark. Int J Clin Pharm. 2013;35:281-288.

9. Larijani B, Zahedi F, Sanjari M, et al. The effect of Ramadan fasting on fasting serum glucose in healthy adults. Med J Malaysia. 2003;58: 678-680.

10. Ahmadani MY, Riaz M, Fawwad A, Hydrie MZ, Hakeem R, Basit A. Glycaemic trend during Ramadan in fasting diabetic subjects: a study from Pakistan. Pak J Biol Sci. 2008;11(16):2044-2047.

11. Al Sifri S, Basiounny A, Echtay A, et al; Ramadan Study Group. The incidence of hypoglycaemia in Muslim patients with type 2 diabetes treated with sitagliptin or a sulphonylurea during Ramadan: a randomized trial. Int J Clin Pract. 2011;65(11):1132-1140.

12. Aravind SR, Al Tayeb K, Ismail SB, et al; Ramadan Study Group. Hypoglycaemia in sulphonylurea treated subjects with type 2 diabetes undergoing Ramadan fasting: a five-country country observational study. Curr Med Res Opin. 2011;27:1237-1242.

13. Aravind SR, Ismail SB, Balamurugan R, et al. Hypoglycemia in patients with type 2 diabetes from India and Malaysia treated with sitagliptin or a sulfonylurea during Ramadan: a randomized, pragmatic study. Curr Med Res Opin. 2012;28(8):1289-1296.

14. Cesur M, Corapcioglu D, Gursoy A, et al. A comparison of glycemic effects of glimepiride, repaglinide, and insulin glargine in type 2 diabetes mellitus during Ramadan fasting. Diabetes Res Clin Pract. 2007;75:141-147.

15. Sari R, Balci MK, Akbas SH, Avci B. The effects of diet, sulfonylurea, and repaglinide therapy on clinical and metabolic parameters in type 2 diabetic patients during Ramadan. Endocr Res. 2004;30: 169-177.
16. Bakiner O, Ertorer ME, Bozkirli E, Tutuncu NB, Demirag NG. Repaglinide plus single-dose insulin glargine: a safe regimen for lowrisk type 2 diabetic patients who insist on fasting in Ramadan. Acta Diabetol. 2009;46(1):63-65.

17. Burden M. Culturally sensitive care: managing diabetes during Ramadan. Br J Community Nurs. 2001;6(11):581-585.

18. Loke SC, Rahim KF, Kanesvaran R, Wong TW. A prospective cohort study on the effect of various risk factors on hypoglycaemia in diabetics who fast during Ramadan. Med J Malaysia. 2010;65(1):3-6.

19. Salehi M, Aulinger BA, D'Alessio DA. Targeting beta-cell mass in type 2 diabetes: Promise and limitations of new drugs based on incretins. Endocr Rev. 2008;29:367-379.

20. Wang Q, Brubaker PL. Glucagon like peptide-1 treatment delays the onset of diabetes in 8 week-old db/db mice. Diabetologia. 2002;45: $1263-1273$.

21. Trumper A, Trumper K, Trusheim H, Arnold R, Goke B, Horsch D. Glucose-dependent insulinotropic polypeptide is a growth factor for beta (INS-1) cells by pleiotropic signaling. Mol Endocrinol. 2001;15: 1559-1570.

22. Krarup T. Immunoreactive gastric inhibitory polypeptide. Endocr Rev. 1988;9:122-134.

23. Ahrén B, Foley J. The islet enhancer vildagliptin: mechanisms of improved glucose metabolism. Int J Clin Pract. 2008;62(Suppl 159): $8-14$.

24. Drucker DJ, Nauck MA. The incretin system: Glucagon-like peptide-1 receptor agonists and dipeptidyl peptidase- 4 inhibitors in type 2 diabetes. Lancet. 2006;368:1696-1705.

25. World Health Organization (WHO). Diabetes Mellitus: Report of a Study Group. Technical Report Series 727. Geneva, Switzerland: WHO; 1985.

26. Expert Committee on the Diagnosis and Classification of Diabetes Mellitus. Report of the expert committee on the diagnosis and classification of diabetes mellitus. Diabetes Care. 1997;20:1183-1197.

27. Mitrakou A, Kelley D, Mokan M, et al. Role of reduced suppression of glucose production and diminished early insulin release in impaired glucose tolerance. $N$ Engl J Med. 1992;326:22-29.

28. Dunning BE, Gerich JE. The role of $\alpha$-cell dysregulation in fasting and postprandial hyperglycemia in type 2 diabetes and therapeutic implications. Endocr Rev. 2007;28:253-283.

29. Larsson H, Berglund G, Ahren B. Glucose modulation of insulin and glucagon secretion is altered in impaired glucose tolerance. $J$ Clin Endocrinol Metab. 1995;80:1778-1782.

30. O' Meara N, Sturis J, VanCouter E, Polonsky K. Lack of control by glucose of ultradian insulin secretory oscillations in impaired glucose tolerance and in non-insulin-dependent diabetes mellitus. J Clin Invest. 1993;92:262-271.

31. Mari A, Sallas WM, Watson C, et al. Vildagliptin, a dipeptidyl peptidase-IV inhibitor, improves model-assessed $\beta$-cell function in patients with type 2 diabetes. J Clin Endocrinol Metab. 2005;90:4888-4894.

32. Bosi E, Camisasca RP, Collober C, et al. Effects of vildagliptin on glucose control over 24 weeks in patients with type 2 diabetes inadequately controlled with metformin. Diabetes Care. 2007;30:890-895.

33. Lukashevich V, Schweizer A, Shao Q, et al. Safety and efficacy of vildagliptin versus placebo in patients with type 2 diabetes and moderate or severe renal impairment: a prospective 24-week randomized placebocontrolled trial. Diabetes Obes Metab. 2011;13(10):947-954.

34. Iwamoto Y, Kashiwagi A, Yamada N, et al. Efficacy and safety of vildagliptin and voglibose in Japanese patients with type 2 diabetes: a 12-week, randomized, double-blind, active-controlled study. Diabetes Obes Metab. 2010;12(8):700-708.

35. Kikuchi M, Abe N, Kato M, et al. Vildagliptin dose dependently improves glycemic control in Japanese patients with type 2 diabetes mellitus. Diabetes Res Clin Pract. 2009;83(2):233-240.

36. Ahre'n B, Foley JE, Bosi E. Clinical evidence and mechanistic basis for vildagliptin's action when added to metformin. Diabetes Obesity Metab. 2011;13(3):193-203. 
37. Zargar A, Basit A, Mahtab H. Sulphonylureas in the management of type 2 diabetes during the fasting month of Ramadan. J Indian Med Assoc. 2005;103:444-446.

38. Zargar AH, Siraj M, Jawa AA, Hasan M, Mahtab H. Maintenance of glycaemic control with the evening administration of a long acting sulphonylurea in male type 2 diabetic patients undertaking the Ramadan fast. Int J Clin Pract. 2010;64:1090-1094.

39. Al Arouj M, Assaad-Khalil S, Buse J, et al. Recommendations for management of diabetes during Ramadan: update. Diabetes Care. 2010;33:1895-1902.

40. Mafauzy M. Repaglinide versus glibenclamide treatment of type 2 diabetes during Ramadan fasting. Diabetes Res Clin Pract. 2002;58: 45-53.

41. The Glimepiride in Ramadan (GLIRA) Study group. The efficacy and safety of glimepiride in the management of type 2 diabetes in Muslim patients during Ramadan. Diabetes Care. 2005;28:421-422.

42. Hassanein M, Hanif W, Malik W, et al. Comparison of the dipeptidyl peptidase-4 inhibitor vildagliptin and the sulphonylurea gliclazide in combination with metformin, in Muslim patients with type 2 diabetes mellitus fasting during Ramadan: results of the VECTOR study. Curr Med Res Opin. 2011;27:1367-1374.

43. Penfornis A, Bourdel-Marchasson I, Quere S, Dejager S. Real-life comparison of DPP4-inhibitors with conventional oral antidiabetics as add-on therapy to metformin in elderly patients with type- 2 diabetes: the HYPOCRAS study. Diabetes Metab. 2012;38:550-557.

44. Devendra D, Gohel B, Bravis V, et al. Vildagliptin therapy and hypoglycaemia in Muslim type 2 diabetes patients during Ramadan. Int $J$ Clin Pract. 2009;63:1446-1450.

45. Ferrannini E, Fonseca V, Zinman B, et al. Fifty-two-week efficacy and safety of vildagliptin vs glimepiride in patients with type 2 diabetes mellitus inadequately controlled on metformin monotherapy. Diabetes Obes Metab. 2009;11:157-166.

46. Malha LP, Taan G, Zantout MS, Azar SM. Glycemic effects of vildagliptin in patients with type 2 diabetes before, during and after the period of fasting in Ramadan. Ther Adv Endocrinol Metab. 2014;5(1):3-9.

47. Anja Schweizer A, Halimi S, Dejager S. Experience with DPP-4 inhibitors in the management of patients with type 2 diabetes fasting during Ramadan. Vasc Health Risk Manag. 2014;10:15-24.

48. Halimi S, Marc Levy M, Huet D, Quéré S, Dejager S. Experience with vildagliptin in type 2 diabetic patients fasting during Ramadan in France: Insights from the VERDI Study. Diabetes Ther. 2013;4:385-398.

49. Al Arouj M, Hassoun AAK, Medlej R, et al. The effect of vildagliptin relative to sulphonylureas in Muslim patients with type 2 diabetes fasting during Ramadan: the VIRTUE study. Int J Clin Pract. 2013;67(10): 957-963.
50. Hassanein M, Abdallah K, Schweizer A. Adouble-blind, randomized trial, including frequent patient-physician contacts and Ramadanfocused advice, assessing vildagliptin and gliclazide in patients with type 2 diabetes fasting during Ramadan: the STEADFAST study. Vasc Health Risk Manag. 2014;10:319-326.

51. Shete A, Shaikh A, Nayeem KJ, et al. Vildagliptin vs sulfonylurea in Indian Muslim diabetes patients fasting during Ramadan. World $J$ Diabetes. 2013;4(6):358-364.

52. Dejager S, Schweizer A. Minimizing the risk of hypoglycemia with vildagliptin: clinical experience, mechanistic basis, and importance in type 2 diabetes management. Diabetes Ther. 2011;2:51-66.

53. Schweizer A, Dejager S, Foley JE, Shao Q, Kothny W. Clinical experience with vildagliptin in the management of type 2 diabetes in a patient population $\geq 75$ years: a pooled analysis from a database of clinical trials. Diabetes Obes Metab. 2011;13:55-64.

54. Dejager S, Schweizer A. Incretin therapies in the management of patients with type 2 diabetes mellitus and renal impairment. Hosp Pract. 2012;40:7-21.

55. Charbonnel B, Schweizer A, Dejager S. Combination therapy with DPP-4 inhibitors and insulin in patients with type 2 diabetes mellitus: what is the evidence? Hosp Pract (1995). 2013;41:93-107.

56. Matthews DR, Dejager S, Ahren B, et al. Vildagliptin add-on to metformin produces similar efficacy and reduced hypoglycaemic risk compared with glimepiride, with no weight gain: results from a 2-year study. Diabetes Obes Metab. 2010;12:780-789.

57. Gaborit B, Dutour O, Ronsin O, et al. Ramadan fasting with diabetes: an interview study of inpatients' and general practitioners' attitudes in the South of France. Diabetes Metab. 2011;37:395-402.

58. Bravis V, Hui E, Salih S, Mehart S, Hassanein M, Devendra D. Ramadan Education and Awareness in Diabetes (READ) programme for Muslims with type 2 diabetes who fast during Ramadan. Diabet Med. 2010;27:327-331.

59. Ahmedani MY, Haque MS, Basit A, Fawwad A, Alvi SF. Ramadan Prospective Diabetes Study: the role of drug dosage and timing alteration, active glucose monitoring and patient education. Diabet Med. 2012;29:709-715.

60. Halimi S, Levy M, Amghar H. Clinical case: beliefs, Ramadan and diabetes mellitus. Ann Endocrinol (Paris). 2004;65(1 Suppl):S68-S73. French.

61. Hassanein M, Bravis V, Hui E, Devendra D. Ramadan-focused education and awareness in type 2 diabetes. Diabetologia. 2009;52:367-368.

62. Hanif W, Malik W, Hassanein M, et al. Treatment adherence with vildagliptin compared to sulphonylurea as add-on to metformin in Muslim patients with type 2 diabetes mellitus fasting during Ramadan. Curr Med Res Opin. 2013;29:807-811.

Diabetes, Metabolic Syndrome and Obesity: Targets and Therapy

Dovepress

\section{Publish your work in this journal}

Diabetes, Metabolic Syndrome and Obesity: Targets and Therapy is an international, peer-reviewed open-access journal committed to the rapid publication of the latest laboratory and clinical findings in the fields of diabetes, metabolic syndrome and obesity research. Original research, review, case reports, hypothesis formation, expert opinion and commentaries are all considered for publication. The manuscript management system is completely online and includes a very quick and fair peer-review system, which is all easy to use. Visit http://www.dovepress.com/testimonials.php to read real quotes from published authors. 